\title{
Comparative, Prospective Study Regarding Efficacy, Safety \& Adverse Effects of Anti-Asthmatic Drugs in Case of Mild to Moderate Chronic Stable Persistent Bronchial Asthma in Adults
}

\author{
Krishnendu Mondal ${ }^{1}$, Rupam Kumar T. A. ${ }^{2}$, Pronoy Sen ${ }^{3}$, Raghul Raj S. ${ }^{4}$ \\ ${ }^{1}$ Department of Critical Care Unit, Burdwan Medical College and Hospital, Bardhaman, West Bengal, India. \\ 2Department of Chest Medicine, Burdwan Medical College and Hospital, Bardhaman, West Bengal, India. \\ ${ }^{3}$ Department of Chest Medicine, Burdwan Medical College and Hospital, Bardhaman, West Bengal, India. \\ ${ }^{4}$ Department of Chest Medicine, Burdwan Medical College and Hospital, Bardhaman, West Bengal, India.
}

\section{ABSTRACT}

\section{BACKGROUND}

Asthma is a heterogeneous disease, usually characterized by chronic airway inflammation, bronchoconstriction and airway hyper responsiveness. The addition of an inhaled corticosteroid (ICS) to an inhaled long-acting $\beta 2$-agonist (LABA) gives optimal control of asthma in most patients. There are few international studies regarding efficacy and safety of LABA/ICS. But in India there is paucity of such studies. Hence the present study was undertaken.

\section{METHODS}

A comparative, prospective, observational study was conducted among 120 patients attending the Out Patient Department of Chest Medicine and Pharmacology of Burdwan Medical College and Hospital, diagnosed as having mild to moderate chronic stable persistent bronchial asthma, receiving combination of LABA and ICS therapy, out of which 16 patients were lost due to follow up, and 104 patients were studied. Patients were divided into 2 groups. Group A received respicaps of combined formoterol $6 \mu \mathrm{g}$ and budesonide $400 \mu \mathrm{g}$ DPI, Group B received combined formoterol $6 \mu \mathrm{g}$ and mometasone $400 \mu \mathrm{g}$ DPI, twice daily. During exacerbations inhaled salbutamol was utilized as rescue medication. Spirometric parameters, clinical parameters, and adverse effects were recorded on three visits (at $4^{\text {th }} 8^{\text {th }}$ and $12^{\text {th }}$ weeks) and analysed by using different statistical tests.

\section{RESULTS}

Comparable clinical improvement of spirometric parameters, Asthma Control Test score of both groups were observed ( $p$-value>0.05). Adverse effects like tremor, pharyngitis, headache, oral candidiasis and dysphonia were recorded among both the groups which was statistically insignificant.

\section{CONCLUSION}

Patients who received ICS with LABA in both groups experienced a statistically significant improvement in symptoms. Improvement was seen in spirometric parameters as well with a comparable degree of safety.

\section{KEY WORDS}

Asthma, Spirometry, Formoterol, Budesonide, Mometasone
Corresponding Author: Dr. Rupam Kumar T. A., \#120, Vivekananda Road Chotonilpur, PO-Sripally, Dist-Purba, Bardhaman-713103, West Bengal, India.

E-mail: rupamkumarta@yahoo.com

DOI: $10.14260 /$ jemds/2020/79

Financial or Other Competing Interests: None.

How to Cite This Article:

Mondal K, Kumar RTA, Sen $P$, et al. Comparative, prospective study regarding efficacy, safety \& adverse effects of antiasthmatic drugs in case of mild to moderate chronic stable persistent bronchial asthma in adults. J. Evolution Med. Dent. Sci. 2020;9(06):347-352, DOI: 10.14260/jemds/2020/79

Submission 15-12-2019,

Peer Review 15-01-2020,

Acceptance 22-01-2020,

Published 10-02-2020. 


\section{BACKGROUND}

Asthma is a heterogeneous disease, usually characterized by variable expiratory airflow limitation, ${ }^{[1]}$ airway inflammation, bronchoconstriction and airway hyper responsiveness, ${ }^{[2]}$ with respiratory symptoms such as wheeze, shortness of breath, chest tightness and cough that vary over time and in intensity. Assessment of asthma should include the assessment of asthma control (both symptom control and future risk of adverse outcomes), treatment issues particularly inhaler technique and adherence, and any comorbidities that could contribute to symptom burden and poor quality of life. Lung function assessed by Pulmonary Function Test (PFT) particularly forced expiratory volume in 1 second (FEV1) as a percentage of predicted, is an important part of the assessment of future risk. National Asthma Education and Prevention Program Guidelines recommend Inhalational Corticosteroids (ICS) as preferred therapy for all severity levels of asthma. The addition of an inhaled corticosteroid (ICS) to an inhaled long-acting $\beta 2$-agonist (LABA) to give optimal control of asthma in most patients and two fixed combination inhalers are increasingly used as a convenient controller in patients with persistent asthma.[3]

Budesonide, an ICS, of which the efficacy and safety of the dry powder (DPI) and metered-dose formulations (pMDI) for the treatment of asthma have been documented/ established. ${ }^{[4]}$ Mometasone furoate (MF) is approved in the US for maintenance treatment of asthma for patients 4 years of age and older.[5] Recent randomized, double-blind, multicentred trials have assessed the efficacy of mometasone furoate delivered by dry powder inhaler (MF-DPI) over 12 weeks in adults and adolescents with mild to moderate persistent asthma.[6] Both Mometasone and Budesonide ICS has low systemic bioavailability, so they are usually well tolerated. And very minimal local adverse events can be produced by them which may be a point of consideration regarding comparing their safety profile. Formoterol, a LABA, has faster onset of action of $<3$ minutes and duration of action for at least 12 hours. [7] There is a strong scientific rationale for the combination of these two drug classes. ICS suppress the chronic inflammation of asthma and reduce airway hyper responsiveness, and this is achieved at low doses in most patients. LABA in addition to their bronchodilator action, also inhibit mast cell mediator release, plasma exudation and may reduce sensory nerve activation. There are few international studies regarding efficacy, safety and adverse effects of LABA/ICS. But in India there is paucity of such studies. Hence the present study is being conducted.

We wanted to assess and compare the efficacy, systemic adverse effects and safety with regard to local adverse events (pharyngitis, oral candidiasis, dysphonia) of Formoterol + Mometasone (group A) and Formoterol + Budesonide (group B) DPI in patients with mild to moderate persistent asthma measured by spirometry \& Asthma Control Test (ACT) scoring system.

\section{METHODS}

This study was a comparative, prospective, observational one conducted among patients of either sex, attending the Out
Patient Department (OPD) of Chest Medicine of Burdwan Medical College and Hospital and who were diagnosed as having mild to moderate chronic stable persistent bronchial asthma receiving combination inhalation therapy of LABA and ICS were recruited in the study after satisfying the inclusion and exclusion criteria.

\section{Inclusion Criteria}

1. Patient 18 years of age \& older.

2. Patients with an established diagnosis of mild to moderate chronic stable persistent bronchial asthma requiring a combination of LABA \& ICS.

3. Patient willing to give consent and available for follow up.

\section{Exclusion Criteria}

1. Patients with severe persistent asthma and severe COPD.

2. Patients with history of severe respiratory tract infection in past 4 weeks

3. Smoking history of 15 or more pack years.

4. Asthmatic patients on oral or parenteral corticosteroids

5. History of hypersensitivity to formoterol, budesonide, mometasone or any ingredients of study formulations.

6. Recent history of myocardial infarction, heart failure, or cardiac arrhythmia requiring treatment and uncontrolled hypertension, severe renal or hepatic disease, active peptic ulcer disease.

7. Pregnant or breastfeeding females.

8. Patients already part or being a part of any clinical study in previous 1 month.

Sample size was initially 120 patients; out of which 16 patients were lost due to follow up and 104 patients with mild to moderate chronic stable persistent bronchial asthma attending Chest Medicine OPD and receiving combination inhalation therapy of LABA \& ICS during the 13 months period and were analysed following inclusion and exclusion criteria. Sample size Calculation was done depending upon the prevalence of asthma in that area in previous few years and also upon the anticipated probability of asthma in population exposed and not exposed to the risk factors, relative risk, confidence interval and precision. Formula used for sample size calculation was: $\mathrm{N}=2 \mathrm{x}\left(\mathrm{Z}_{\alpha}+\mathrm{Z}_{\beta}\right){ }^{2} \mathrm{x}\left\{\mathrm{P}_{1}\left(1-\mathrm{p}_{1}\right)+\right.$ $\left.\mathrm{P}_{2}\left(1-\mathrm{p}_{2}\right)\right\} /\left(\mathrm{p}_{1}-\mathrm{p}_{2}\right)^{2}$. Patients lost to follow up were tried to track via telephone, email and sending letters to their postal addresses but failed to do so.

The study protocol along with the CRF and ICF were submitted to the Institutional Ethics Committee (IEC) of Burdwan Medical College and Hospital, Burdwan, for approval. Study was started only after such approval had been obtained in writing by the concerned authority.

Recruitment was subjected to satisfactory completion of the informed consent process. Patients were selected and divided into 2 group by stratified random sampling method. Group A received respicaps of combined formoterol $6 \mu \mathrm{g}$ and budesonide $400 \mu \mathrm{g}$ DPI, twice daily and group B received respicaps of combined formoterol $6 \mu \mathrm{g}$ and mometasone 400 $\mu \mathrm{g}$ DPI, twice daily were administered through Rotahaler device. If asthma symptoms were not controlled and/or during exacerbations an inhaled, short-acting beta- 2 agonist salbutamol was utilized as rescue medication. For patients who did not respond adequately to the initial dose of therapy 
even after 2 weeks, higher doses of steroid were given to provide additional symptom improvement in asthma control, and they were excluded from the study. The efficacy and safety of the study drug combination were assessed periodically through monitoring of the primary and secondary efficacy variables throughout the study period.

\section{Assessment Parameters}

The following parameters were assessed at baseline and at follow-up visits.

\begin{tabular}{|c|c|c|c|c|}
\hline \multirow[b]{2}{*}{ Parameters } & \multirow[b]{2}{*}{$\begin{array}{c}\text { Baseline } \\
\text { (Day 0) }\end{array}$} & \multicolumn{3}{|c|}{ Follow up } \\
\hline & & $\begin{array}{l}1^{\text {st }}\left(4^{\text {th }}\right. \\
\text { Week })\end{array}$ & $\begin{array}{l}2^{\text {nd }}\left(8^{\text {th }}\right. \\
\text { Week })\end{array}$ & $\begin{array}{l}3^{\text {rd }}\left(12^{\text {th }}\right. \\
\text { Week })\end{array}$ \\
\hline $\begin{array}{l}\text { Clinical signs \& symptoms by Asthma } \\
\text { Control Test(ACT) Score }\end{array}$ & $\sqrt{ }$ & $\sqrt{ }$ & $\sqrt{ }$ & $\sqrt{ }$ \\
\hline Machinery Spirometry (including FEV1) & $\sqrt{ }$ & $\sqrt{ }$ & $\sqrt{ }$ & $\sqrt{ }$ \\
\hline Haematological (Hb\%) & $\sqrt{ }$ & - & - & $\sqrt{ }$ \\
\hline Biochemical(Na+, K+, Creatinine) & $\sqrt{ }$ & - & - & $\sqrt{ }$ \\
\hline $\begin{array}{l}\text { Adverse events (e.g. pharyngitis, oral } \\
\text { candidiasis, tremor, palpitation, } \\
\text { headache, dysphonia) }\end{array}$ & $\sqrt{ }$ & - & - & $\sqrt{ }$ \\
\hline Concomitant medication(s) & $\sqrt{ }$ & $\sqrt{ }$ & $\sqrt{ }$ & $\sqrt{ }$ \\
\hline
\end{tabular}

\section{Concomitant Medication}

Patients were permitted to use the inhaled salbutamol as a rescue medication during exacerbations. The use of inhaled salbutamol recorded in the daily dairy provided to the patient and same data will be filled in the case record form during the follow up visits. Therapy for concomitant diseases like hypertension, diabetes and ischemic heart disease were permitted. Other supportive therapy as deemed essential was also permitted. All such concomitant medications taken by the patients were recorded in the CRF.

\section{Statistical Analysis}

Data were collected and compiled. It was presented in tabular form as well as graphical state. Data were entered in Microsoft Excel 2013 and analysis was done using different statistical methods like Unpaired t test, Mann Whitney U Test, Friedman's ANOVA test, Repeated measure ANOVA test, Wilcoxon matched pairs signed ranks test and Paired t test. A p-value of $<0.05$ was considered as statistically significant.

\section{RESULTS}

\begin{tabular}{|c|c|c|c|c|c|}
\hline $\begin{array}{c}\text { Age Group } \\
\text { (Years) }\end{array}$ & $\begin{array}{c}\text { Group A } \\
(\mathbf{n = 5 6 )} \\
\text { Male }\end{array}$ & $\begin{array}{c}\text { Group A } \\
(\mathbf{n = 5 6 )} \\
\text { Female }\end{array}$ & $\begin{array}{c}\text { Group B } \\
(\mathbf{n = 4 8 )} \\
\text { Male }\end{array}$ & $\begin{array}{c}\text { Group B } \\
\mathbf{( n = 4 8 )} \\
\text { Female }\end{array}$ & $\mathbf{p}$ \\
\hline $20-30$ & 10 & 6 & 12 & 8 & \\
\hline $31-40$ & 9 & 7 & 5 & 3 & \\
\hline $41-50$ & 9 & 4 & 8 & 4 & \multirow{2}{*}{0.2406} \\
\hline $51-60$ & 2 & 2 & 2 & 2 & \\
\hline$>60$ & 4 & 3 & 3 & 1 & \\
\hline Total & $\mathbf{3 4 2 2}$ & $\mathbf{2 2}$ & $\mathbf{3 0}$ & 18 & \\
\hline \multicolumn{7}{|c|}{ Table 1. Distribution of the Study Population } \\
\hline
\end{tabular}

There was no statistically significant difference in age and sex distribution in both treatment groups $(p=0.2406)$ [p value derived by applying Unpaired t test]. Mean weight and height of both the groups did not show any statistically significant difference $(\mathrm{p}=0.7842$ for height $\& \mathrm{p}=0.6041$ for weight) [p value derived by applying Mann Whitney U test].

\begin{tabular}{|c|c|c|c|}
\hline FEV1 Measurements & $\begin{array}{c}\text { Group A } \\
\text { (n=56) } \\
\text { (Mean } \pm \text { SD) }\end{array}$ & $\begin{array}{c}\text { Group B } \\
\text { (n=48) } \\
\text { (Mean } \pm \text { SD) }\end{array}$ & $\begin{array}{c}\text { p Value (by } \\
\text { Applying Mann } \\
\text { Whitney U test) }\end{array}$ \\
\hline $\begin{array}{c}\text { Baseline value of FEV1 } \\
\text { (\% of the predicted value) }\end{array}$ & $1.749 \pm 1.061$ & $1.996 \pm 0.484$ & 0.1451 \\
\hline $\begin{array}{c}\text { FEV1 at end of 4 weeks } \\
\text { (\% of the predicted value) }\end{array}$ & $2.006 \pm 1.102$ & $2.294 \pm 0.468$ & 0.2118 \\
\hline $\begin{array}{c}\text { FEV1 at end of } 8 \text { weeks } \\
\text { (\% of the predicted value) }\end{array}$ & $2.295 \pm 1.113$ & $2.631 \pm 0.471$ & 0.1934 \\
\hline $\begin{array}{c}\text { FEV1 at end of } 12 \text { weeks } \\
\text { (\% of the predicted value) }\end{array}$ & $2.577 \pm 1.129$ & $2.813 \pm 0.441$ & 0.4672 \\
\hline $\begin{array}{c}\text { P value (by applying repeated } \\
\text { measures Friedman's ANOVA) }\end{array}$ & $<0.0001$ & $<0.0001$ & \\
\hline
\end{tabular}

Table 2. FEV1 Measured by Spirometer among the Two Groups at the Start of the Treatment and During the Follow-Up Period

It was predicted from table 2 that there was a gradual improvement in the FEV1 from baseline to 12 weeks of treatment in both the groups and the difference was found to be statistically. Significant $(p<0.0001)$. The patients treated both groups showed a not significant difference in improvement in FEV1 when compared to each other $(p=0.4672)$. $p$ Values of the same groups in the time series from baseline to the end of treatment were determined by applying repeated measures Friedman's ANOVA test. And the $P$ values for between group comparison were determined by applying Mann Whitney U test.

\begin{tabular}{|c|c|c|c|}
\hline ACT Score & $\begin{array}{c}\text { Group A } \\
(\mathbf{n = 5 6 )} \\
(\text { Mean } \pm \text { SD) }\end{array}$ & $\begin{array}{c}\text { Group B } \\
(\mathbf{n = 4 8 )} \\
(\text { Mean } \pm \text { SD })\end{array}$ & $\begin{array}{c}\text { p Value (by } \\
\text { Applying Mann } \\
\text { Whitney U Test) }\end{array}$ \\
\hline Baseline value & $12.375 \pm 2.196$ & $11.979 \pm 1.379$ & 0.267 \\
\hline At the end of 4 weeks & $14.625 \pm 1.893$ & $14.021 \pm 3.091$ & 0.2426 \\
\hline At the end of 8 weeks & $16.536 \pm 1.618$ & $15.958 \pm 2.689$ & 0.1973 \\
\hline At end of 12 weeks & $18.071 \pm 1.399$ & $17.083 \pm 2.688$ & 0.0536 \\
\hline $\begin{array}{c}\text { p value (by applying Repeated } \\
\text { measure ANOVA test) }\end{array}$ & $<0.0001$ & $<0.0001$ & \\
\hline Table 3. ACT Score Analysis of Two Groups at the Start of the \\
Treatment and During the Follow-Up Period
\end{tabular}

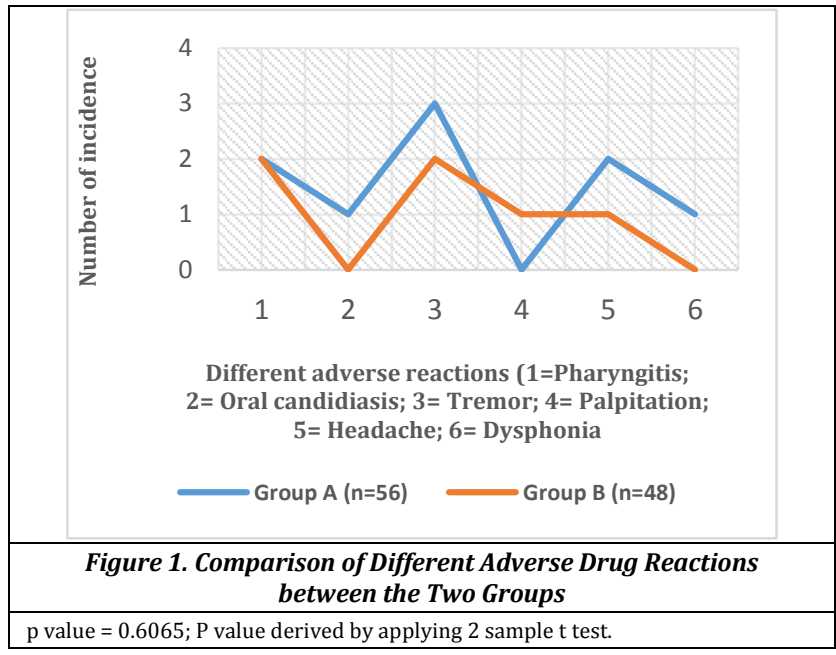

It was predicted from table 4 that there was a gradual improvement in the ACT score from baseline to 12 weeks of treatment in both the groups and the difference was found to be statistically significant $(\mathrm{p}<0.0001)$. The patients treated both groups showed a not quite significant difference in improvement in FEV1 when compared to each other $(p=0.0536)$. $P$ values of the same groups from baseline to the end of treatment were determined by applying Wilcoxon matched pairs signed ranks test. And the $P$ values for between group comparison were determined by applying Mann Whitney U test. 


\begin{tabular}{|c|c|c|c|}
\hline Parameters & $\begin{array}{c}\text { Group A } \\
(n=56) \\
(\text { Mean } \pm S D)\end{array}$ & $\begin{array}{c}\text { Group B } \\
(n=48) \\
(\text { Mean } \pm \text { SD) }\end{array}$ & $\begin{array}{l}\text { p Value (by } \\
\text { Applying } \\
\text { Unpaired t } \\
\text { Test) }\end{array}$ \\
\hline Haemoglobin (Baseline value) & $12.343 \pm 0.913$ & $12.423 \pm 0.939$ & 0.6611 \\
\hline Haemoglobin (At end of 12 weeks) & $12.329 \pm 0.843$ & $12.365 \pm 0.821$ & 0.8265 \\
\hline P value (by applying Paired t Test) & 0.6255 & 0.1670 & \\
\hline $\begin{array}{c}\text { Creatinine (Baseline value) (in } \\
\mathrm{mg} / \mathrm{dl})\end{array}$ & $0.95 \pm 0.097$ & $0.96 \pm 0.097$ & 0.4033 \\
\hline $\begin{array}{l}\text { Creatinine (At end of } 12 \text { weeks) } \\
\text { (in } \mathrm{mg} / \mathrm{dl} \text { ) }\end{array}$ & $0.95 \pm 0.089$ & $0.96 \pm 0.079$ & 0.8411 \\
\hline $\begin{array}{l}\mathrm{P} \text { value (by applying Wilcoxon } \\
\text { matched pairs signed ranks test) }\end{array}$ & 0.8199 & 0.4047 & \\
\hline $\begin{array}{l}\text { Sodium (Na+) (Baseline value) } \\
\text { (in } \mathrm{mEq} / \mathrm{L})\end{array}$ & $139.18 \pm 2.279$ & $138.76 \pm 2.49$ & 0.3752 \\
\hline $\begin{array}{l}\text { Sodium }(\mathrm{Na}+\text { ) (At end of } 12 \text { weeks) } \\
\text { (in } \mathrm{mEq} / \mathrm{L} \text { ) }\end{array}$ & $139.22 \pm 2.278$ & $138.79 \pm 2.454$ & 0.3661 \\
\hline P value (by applying Paired t Test) & 0.1484 & 0.1679 & \\
\hline $\begin{array}{c}\text { Potassium (K+) (Baseline value) } \\
\text { (in mEq/L) }\end{array}$ & $4.14 \pm 0.426$ & $4.138 \pm 0.416$ & 0.9194 \\
\hline $\begin{array}{l}\text { Potassium (K+) (At end of } 12 \text { weeks) } \\
\text { (in mEq/L) }\end{array}$ & $4.159 \pm 0.435$ & $4.15 \pm 0.441$ & $>0.9999$ \\
\hline $\begin{array}{l}\text { P value (by applying Wilcoxon } \\
\text { matched pairs signed ranks test) }\end{array}$ & 0.1637 & 0.4504 & \\
\hline \multicolumn{4}{|c|}{$\begin{array}{c}\text { Table 4. Comparative Analysis of the Haematological and Renal } \\
\text { Parameters at the Start of Treatment and and at the End of } 12 \text { Weeks } \\
\text { of Treatment between Two Groups }\end{array}$} \\
\hline
\end{tabular}

$p$ values of within group before-after comparison in case of haemoglobin level was determined from Paired $t$ Test. And the $p$ values for between group comparison were determined by applying Unpaired t Test. p values of within group beforeafter comparison in case of creatinine level was determined from Wilcoxon matched pairs signed ranks test. And the $p$ values for between group comparison were determined by applying Unpaired $t$ Test. $p$ values of within group beforeafter comparison in case of sodium level was determined from Paired t Test. And $p$ values of within group before-after comparison in case of potassium level was determined from Wilcoxon matched pairs signed ranks test. The $p$ values for between group comparison in case of sodium level was determined by applying Unpaired t Test. And $\mathrm{p}$ values for between group comparison in case of potassium level was determined by Mann Whitney $U$ test. It was predicted from figure 1 that total number of adverse events was higher in the patients of group A than the other group, but of not significant one. Tremor was the most common (5.36\%) adverse effect noted in the study group A; and Pharyngitis and Tremor were equally ( $4.167 \%$ each) noted as adverse reactions in the patients of group $B$.

\section{DISCUSSION}

A comparative analysis between two combined inhalational regimes of LABA \& ICS was done in this study. Multiple studies have shown the efficacy and safety of combining LABA with ICS in the management of bronchial asthma. Each compound was found to be effective when given alone or combined with other drugs. Budesonide, a well-known ICS in asthma has been extensively investigated and has been shown to be effective in controlling asthma in adults. ${ }^{[8-10]} \mathrm{Few}$ studies had been carried out to document the efficacy of mometasone alone ${ }^{[11-14]}$ or along with formoterol[15] which shown improvement in lung function there by reducing asthma symptoms and need for rescue medication. However, formoterol is associated with a faster onset of action than ICS.[16,17] As recently reviewed by Murphy and Bender,[18] several surveys have indicated that rapid onset of action is a highly desirable attribute of asthma therapy from a patient perspective. The perception that controller medication is working immediately is a strong predictor of overall treatment satisfaction and may lead to improved medication adherence.[18]

Regarding demographic profile of this study it had been noted that there was male preponderance over females in both groups which is similar to a parallel study ${ }^{[19]}$ and in contrast to another similar study conducted by Bosquet et $\mathrm{al}[20]$ win which there was female preponderance. Majority of the patients were in the age group of $20-30$ years and mean age in both groups were almost similar $(39.16 \pm 12.77$ in group $A$ and $36.77 \pm 13.56$ in group B) indicating preponderance to the younger age group in both the groups which is in coherence with the study done by Bosquet et al [20] and in contrast to an another study done by Sivasankari et al.[21] The mean weight and height of both the groups did not show any statistical significant difference that is similar to an another study Sivasankari et al.[19]

In the present study, there is a significant improvement in FEV1 (primary efficacy variable) at the end of $12^{\text {th }}$ weeks in both the groups which is in accordance to some other studies done by Sivasankari et al[19] and Bosquet et al.[20] Zeidler et al[22] and Kemp et al[23],both these studies documented significant improvement in lung function with mometasone/ formoterol combination. The treatment arm with mometasone/formoterol shown similar outcome as there is no statistically significant difference in improvement of FEV1, when compared to budesonide/formoterol arm. This is in accordance with Jorge Maspero et al ${ }^{[24]}$ who proved that mometasone is not inferior to Fluticasone by an improvement in pulmonary function tests. A study by comparing mometasone furoate with other long acting steroids like budesonide, fluticasone, beclomethasone has proved that mometasone has equivalent efficacy by an improvement in FEV1. All of these support our data that mometasone combination is not at all inferior than budesonide combination in terms of improvement in lung function. ${ }^{[5,25,26]}$ As all patients in the study were using recommended (with label) other doses of prescribed LABA/ICS to control their asthma prior to beginning this trial, the additional improvement obtained with Mometasone combination DPI treatment over the previous therapeutic regimen of LABA/ICS was considered to be clinically meaningful. Some of this improvement may have resulted from the increased compliance that occurs when patients enter a clinical study.

In our study, the subjective assessment was made based on the symptom score i.e. Asthma Control Test (ACT) score which was designed by GINA guidelines[27-29] which also determine the Quality Of Life (QOL) in asthma. The symptom scores were improved on each successive visits and was significantly improved in both the study groups at the end of 12 weeks compared with baseline measurements. And there was no significant difference between the two groups in improvement of symptoms control and need for rescue inhaler medication at the end of 12 weeks study duration, suggesting that Mometasone/Formoterol combination was equivalently efficacious in asthma symptoms control when compared to Budesonide/Formoterol one. Compared with baseline measurements Sivasankari et al[19] shown even 
significantly better symptom control of mometasone/ formoterol group than the budesonide/formoterol one.

In this study it has been found that the potential benefits overweigh the risk. However, the adverse effects noted commonly in this study were pharyngitis, oral candidiasis, tremor, headache, palpitation and dysphonia with the use of ICS \& LABA. No significant changes were noted regarding haematological, renal and electrolyte parameters in both groups and was of no statistically significant difference. In our study population most of the patients of budesonide/formoterol group experienced tremor (5.36\%), followed by pharyngitis (3.57\%) and headache (3.57\%); only $1.79 \%$ of patients had been suffered from oral candidiasis and dysphonia each. In mometasone/formoterol group $4.167 \%$ of patients suffered from tremor and pharyngitis each; no one had experienced oral candidiasis and dysphonia. The tolerance was good and minor adverse effects were treated symptomatically and observations were almost similar found in studies conducted by Bousquetetal[20] and Chervinskyetal.[30] Dysphonia was the most commonly found treatment related adverse event noted in the Bousquetetal[20] study.

\section{CONCLUSIONS}

Patients who received ICS with LABA in both groups experienced a statistically significant improvement in symptoms. Improvement was seen in spirometric parameters as well with a comparable degree of safety. This 12 -week study also showed that inhaled mometasone furoate along with formoterol administered by a novel breath actuated DPI was effective and well tolerated by adults who were previously maintained on daily inhaled corticosteroids for treatment of moderate persistent asthma as the budesonide/formoterol combination in terms of improvement in lung function, control of asthma symptoms with a comparable degree of safety.

\section{Limitations}

The trial was of an open-label design and is, therefore, subject to typical limitations inherent with open-label study. While the study was open-label, subjects were expected to be more familiar with the treatment administration of budesonide/formoterol DPI than the use of mometasone/formoterol DPI test product.

\section{REFERENCES}

[1] Global Initiative for Asthma. Global Strategy for Asthma Management and Prevention, 2016. www.ginasthma.org

[2] National Asthma Education and Prevention Program. Expert Panel Report 3 (EPR-3): Guidelines for the Diagnosis and Management of Asthma-Summary Report 2007. J Allergy Clin Immunol 2007;120(5 Suppl):S94138.

[3] Barnes PJ. Scientific rationale for inhaled combination therapy with long-acting beta2-agonists and corticosteroids. Eur Respir J 2002;19(1):182-91.
[4] Eseverri JL, Botey J, Marin AM. Budesonide: treatment of bronchial asthma during childhood. Allergy Immunol 1995;27(4):129-35.

[5] Tan RA, Corren J. Mometasone furoate in the management of asthma: a review. Ther Clin Risk Manag 2008;4(6):1201-8.

[6] Sharpe M, Jarvis B. Inhaled mometasone furoate: a review of its use in adults and adolescents with persistent asthma. Drugs 2001;61(9):1325-50.

[7] Wolfe J, Laforce C, Friedman B, et al. Formeterol, 24 microg bid, and serious asthma exacerbations: similar rates compared with formoterol, 12 microg bid, with and without extra doses taken on demand and placebo. Chest 2006;129(1):27-38.

[8] Edwards IR, Aronson JK. Adverse drug reactions: definitions, diagnosis and management. Lancet 2000;356(9237):1255-9.

[9] Tripathi KD. Adverse drug effects. In: Tripathi KD, edr. Essentials of Medical Pharmacology. $6^{\text {th }}$ edn. New Delhi: Jaypee Brothers Medical Publishers (P) Ltd., 2006: p. 7886.

[10] Chabner BA, Bertino J, Cleary J, et al. Cytotoxic agents. In: Brunton LL, Chabner BA, Knollmann BC, eds. The pharmacological basis of therapeutics. $12^{\text {th }}$ edn. New York: McGraw-Hill Medical Publisher 2011: p. 1677-730.

[11] Uppasala Monitoring Centre. The use of the WHO-UMC system for standardised case causality assessment [monograph on the internet]. Uppsala: Uppsala Monitoring Centre, 2005 [cited 2008 Jul 7]. http://www.WHO-UMC.org/graphics/4409.

[12] Naranjo CA, Busto U, Sellers EM, et al. A method for estimating the probability of adverse drug reactions. Clin Pharmacol Ther 1981;30(2):239-45.

[13] Aaronson D, Kaiser H, Dockhorn R, et al. Effects of budesonide by means of the Turbuhaler on the hypothalamic pituitary-adrenal axis in asthmatic subjects: a dose-response study. J Allergy Clin Immunol 1998;101(3):312-9.

[14] Nelson HS, Bernstein IL, Fink J, et al. Oral glucocorticosteroid- sparing effect of budesonide administered by Turbuhaler: a double-blind, placebocontrolled study in adults with moderate-to-severe chronic asthma. Pulmicort Turbuhaler Study Group. Chest 1998;113(5):1264-71.

[15] Busse WW, Chervinsky P, Condemi J, et al. Budesonide delivered by Turbuhaler is effective in a dose-dependent fashion when used in the treatment of adult patients with chronic asthma. J Allergy Clin Immunol 1998;101(4 Pt 1):457-63.

[16] Nayak AS, Banov C, Corren J, et al. Once-daily mometasone furoate dry powder inhaler in the treatment of patients with persistent asthma. Ann Allergy Asthma Immunol 2000;84(4):417-24.

[17] Pedersen S, O'Byrne P. A comparison of the efficacy and safety of inhaled corticosteroids in asthma. Allergy 1997;52(39 Suppl):1-34.

[18] Bernstein DI, Hébert J, Cheema A, et al. Efficacy and onset of action of mometasone furoate/ formoterol and fluticasone propionate/ salmeterol combination treatment in subjects with persistent asthma. Allergy Asthma \& Clin Immunol 2011;7(1):21. 
[19] Chowdhury BA, Pan DG. The FDA and safe use of longacting betaagonists in the treatment of asthma. $\mathrm{N}$ Engl J Med 2010;362(13):1169-71.

[20] Walters EH, Gibson PG, Lasserson TJ, et al. Long-acting beta2- agonists for chronic asthma in adults and children where background therapy contains varied or no inhaled corticosteroid. Cochrane Database Syst Rev 2007;24(1):CD001385.

[21] O'Byrne PM, Barnes PJ, Rodriguez-Roisin R, et al. Low dose inhaled budesonide and formoterol in mild persistent asthma: the OPTIMA randomized trial. Am J Respir Crit Care Med 2001;164(8 Pt 1):1392-7.

[22] Cote C, Pearle JL, Sharafkhaneh A, et al. Faster onset of action of formoterol versus salmeterol in patients with chronic obstructive pulmonary disease: a multicenter, randomized study. Pulm Pharmacol Ther 2009;22(1):449.

[23] Van Noord JA, Smeets JJ, Raaijmakers JA, et al. Salmeterol versus formoterol in patients with moderately severe asthma: onset and duration of action. Eur Respir J 1996;9(8):1684-8.

[24] Murphy KR, Bender BG. Treatment of moderate to severe asthma: patient perspectives on combination inhaler therapy and implications for adherence. J Asthma Allergy 2009;2:63-72.
[25] Sivasankari V, Manivannan E, Sivakumar V. Comparative study to assess the efficacy and safety of mometasone/ formoterol and budesonide/ formoterol as combination therapy in moderate bronchial asthma patients - a prospective, open label comparative study. Int J Pharm Bio Sci 2016;7(3):1-5.

[26] Bousquet J, D'Urzo A, Hebert J, et al. Comparison of the efficacy and safety of mometasone furoate dry powder inhaler to budesonide Turbuhaler. Eur Respir J 2000;16(5):808-16.

[27] Thomas M, Kay S, Pike J, et al. The Asthma Control Test (ACT) as a predictor of GINA guideline-defined asthma control: analysis of a multinational cross-sectional survey. Prim Care Respir J 2009;18(1):41-9.

[28] Nathan RA, Sorkness CA, Kosinski M, et al. Development of the asthma control test: a survey for assessing asthma control. J Allergy Clin Immunol 2004;113(1):59-65.

[29] Schatz M, Kosinski M, Yarlas AS, et al. The minimally important difference of the Asthma Control Test. J Allergy Clin Immunol 2009;124(4):719-23.e1.

[30] Zeidler M, Corren J, Tashkin DP. Use of mometasone furoate administered via a dry powder inhaler in the treatment of asthma. Curr Med Res Opin 2010;26(6):1295-305. 